\title{
KARAKTERISTIK GENERATOR SINKRON YANG BERBEBAN BERAT DAN TIDAK KONSTAN
}

\author{
Perawati \\ Dosen Tetap Yayasan pada Program Studi Teknik Elektro \\ Fakultas Teknik Universitas PGRI Palembang \\ e-mail : perawati80@gmail.com
}

\begin{abstract}
ABSTRAK
Generator sinkron umumnya mempunyai beban yang konstan, tetapi ada saatnya, generator tersebut memikul beban yang tidak konstan atau berubah - ubah, misalnya ketika mengelas. Besar beban generator akan tergantung pada kontak antara elektroda las dan beban. Ketika generator berbeban (beban pengelasan) tegangan yang diukur lebih kecil daripada tegangan yang dibangkitkan, hal itu terjadi karena adanya jatuh tegangan di saluran, elektroda dan beban. Pada saat itu kecepatan rotorpun akan berkurang, karena arus beban akan memberikan gaya yang arahnya berlawanan dengan arah putaran prime mover. Dari hasil perhitungan dapat diketahui bahwa tegangan kerja mengalami penurunan untuk elektroda $2,6 \mathrm{~mm}$ dari $30 \mathrm{~V}$ menjadi $11 \mathrm{~V}$ dan untuk elektroda $3,2 \mathrm{~mm}$ dari $30 \mathrm{~V}$ menjadi $9 \mathrm{~V}$. Hal ini disebabkan adanya arus yang diserap beban dan menyebabkan jatuh tegangan. Saat generator berbeban (beban pengelasan) tegangan yang diukur lebih kecil daripada tegangan yang dibangkitkan, karena adanya jatuh tegangan di saluran, elektroda dan beban.
\end{abstract}

Kata kunci : generator sinkron, jatuh tegangan, kepala las

\section{ABSTRACT}

Synchronous generator usually has a constant load, but sometimes the load is changed, for example when it is welding. The magnitude of load generator will depend on welding between electrode and load contact. When the generator has welding load, the measured voltage is smaller than generated voltage, it happens because of drop voltage on line, electrode and load. At the same time, the rotor speed will decrease, because the load current will give opposite force with the direction of the prime mover. From the result of calculation, the working voltage decrease for 2,6 mm electrode from $30 \mathrm{~V}$ to $11 \mathrm{~V}$ and for $3,2 \mathrm{~mm}$ electrode from $30 \mathrm{~V}$ to $9 \mathrm{~V}$. It is caused by the current absorbed by load and will drop the voltage. When generator is loaded, the voltage is measured lower than the generated voltage because the voltage is dropped on the line, electrode and load.

Keywords : synchronous generator, drop voltage, welding head

\section{PENDAHULUAN}

Generator biasanya mempunyai beban yang konstan, misalnya beban lampu, pompa. Tetapi pada saat-saat tertentu, misalnya di work shop, generator mempunyai beban yang tidak konstan. Saaat generator mempunyai beban yang berubah-ubah, misalnya saat mengelas, besarnya beban tergantung pada kontak antara elektroda las dan beban. Hal ini akan menyebabkan kerusakan karena perubahan beban yang mendadak. Hal tersebut menjadi latar belakang dari penelitian ini yaitu tentang analisis kerja generator sinkron yang mempunyai beban yang berat dan tidak konstan.

Pada penelitian ini, akan diukur dan dihitung parameter generator tersebut, yaitu tegangan,arus, dan putaran 


\section{TINJAUAN PUSTAKA}

\section{Dasar-Dasar Generator Sinkron}

Generator adalah mesin listrik yang dapat mengubah energi mekanik menjadi energi listrik dengan perantara media elektromagnet.

Generator sinkron merupakan mesin pembangkit yang paling banyak digunakan, karena pertimbangan tertentu, seperti :

- Terdapat dipasaran dengan berbagai macam tingkat daya

- Harganya relatif lebih murah

- Pengoperasiannya dan pemeliharaanya mudah dan murah

Generator kecepatan rendah, misalnya generator yang digerakkan mesin diesel atau turbin air mempunyai mempunyai rotor dengan kutub medan menonjol (kutub sepatu). Generator dengan kecepatan tinggi mempunyai rotor silinder (Eugene C Lister, 1988 : 200)

\section{PRINSIP KERJA GENERATOR SINKRON}

Mesin sinkron mempunyai kumparan medan pada rotor dan kumparan jangkar pada stator. Kumparan jangkar mempunyai bentuk yang sama dengan mesin induksi, sedangkan sedangkan kumparan medannya dapat berbentuk kutub sepatu atau silinder (Zuhal, 1990: 130)

Generator sinkron bekerja berdasarkan prinsip sbb :

1. Kumparan medan pada rotor akan mensuplai arus searah ke kumparan medan yang akan menimbulkan fluks.

2. Penggerak mula (Prime Mover) yang terkopel ke rotor beroperasi sehingga rotor berputar pada kecepatan nominalnya.

$\mathrm{N}=\frac{1 \quad f}{r}$

dimana: $\quad n=$ Kecepatan putar rotor $(\mathrm{rpm})$

$$
\begin{aligned}
& P=\text { Jumlah kutub rotor } \\
& f=\text { frekuensi }(\mathrm{Hz})
\end{aligned}
$$

3. Perputaran rotor akan memutar medan magnet yang dihasilkan kumparan medan. Medan putar yang dihasilkan rotor akan diinduksikan pada kumparan jangkar sehingga pada kumparan jangkar terjadi fluks magnetik yang berubah-ubah. Perubahan fluks magnetik yang melingkupi kumparan akan menimbulkan ggl induksi pada ujung-ujung kumparan wahyukr.staff.gunadarma.ac.id/Downloads/.../5+TEORI+GENERATOR+SINKRON.p...

\section{Konstruksi Generator Sinkron}

Secara garis besar, generator sinkron terdiri dari stator, rotor, dan celah udara. Stator adalah bagian yang diam sedangkan rotor adalah bagian yang berputar. Celah udara adalah ruang antara stator dan rotor.

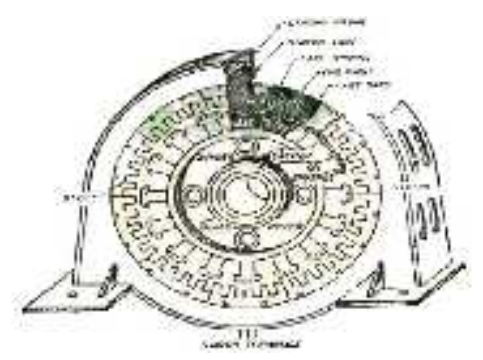

Gambar 1. Konstruksi Generator Sinkron

wahyukr.staff.gunadarma.ac.id/Downloads/.../5+TEORI+GENERATOR+SINKRON.p... 
1. STATOR

Stator terdiri dari beberapa komponen utama, yaitu :

a. Rangka Stator

Rangka stator adalah penyangga inti jangkar generator

b. Inti Stator

Inti stator terdiri dari laminasi-laminasi yang terpasang pada rangka stator.

c. Alur (slot) dan Gigi

Alur dan gigi merupakan tempat meletakkan kumparan stator.

Ada 3 (tiga) bentuk alur stator yaitu terbuka, setengah terbuka, dan tertutup. Seperti pada Gambar 2 berikut :

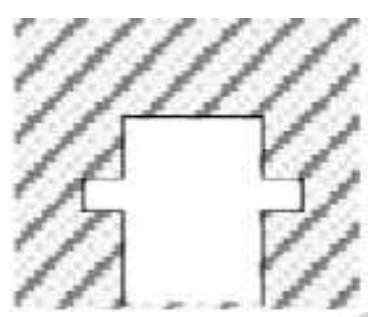

Terbuka

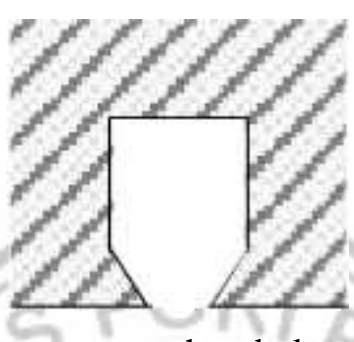

setengah terbuka

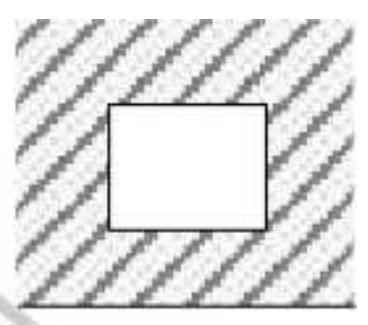

Tertutup

Gambar 2. Macam-macam bentuk alur wahyukr.staff.gunadarma.ac.id/Downloads/.../5+TEORI+GENERATOR+SINKRON.p...

d. Kumparan Stator (Kumparan Jangkar)

Merupakan tempat terjadi ggl induksi

\section{ROTOR}

Rotor terdiri dari tiga komponen utama yaitu :

a. Slip Ring

Slip ring adalah cincin dari logam yang melingkari poros rotor yang saling terpisah (diisolasi).

Pada slip ring inilah dipasang terminal kumparan rotor yang kemudian melalui sikat dihubungkan ke sumber arus dc.

b. Kumparan Rotor (kumparan medan)

Kumparan medan rotor inilah yang berperan utama dalam menghasilkan medan magnet

c. Poros Rotor

Kumparan medan diletakkan pada poros rotor yang berbentuk slot-slot

Pada dasarnya, rotor pada generator sinkron merupakan suatu elektromanet. Kutub medan magnet rotor terbagi menjadi salient (kutub sepatu) dan dan non salient (rotor silinder). Kutub sepatu generator sinkron ditunjukkan pada gambar berikut :
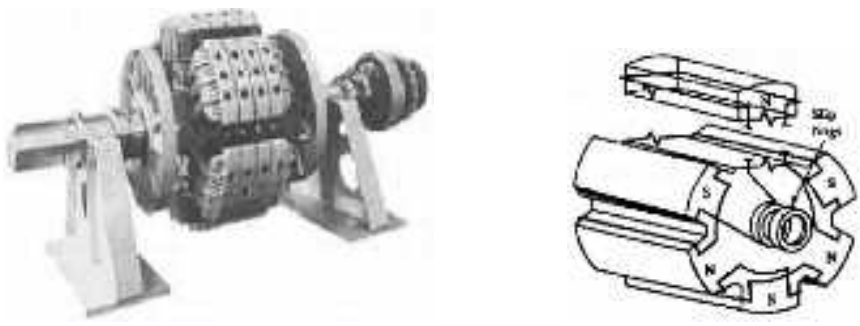

Gambar 3. Rotor salient (kutub sepatu) pada generator sinkronmercubuana.ac.id/files/.../2100601_ELektronika\%20\&\%20TTL_Modul_013.docx 
Pada rotor kutub sepatu, konstruksi kutub magnetnya menonjol dari permukaan rotor, sedangkan pada rotor kutub silinder, kutub magnetnya rata. Pada umumnya, rotor silinder dipakai untuk rotor yang mempunyai 2 atau 4 kutub, dan untuk rotor kutub sepatu untuk rotor yang mempunyai 4 kutub atau lebih. Selain itu, pemilihan konstruksi rotor dipengaruhi juga oleh : kecepatan putar prime mover, frekuensi dan rating daya generator sinkron tersebut. Untuk generator yang mempunyai kecepatan diatas $1500 \mathrm{rpm}$, frekuensi $50 \mathrm{~Hz}$ dengan rating daya kurang lebih 10MVA, maka digunakan generator rotor silinder. Sedangkan untuk generator dengan daya kurang dari 10 MVA dan kecepatannya rendah, digunakangenerator sinkron jenis rotor kutub sepatu. Generator sinkron rotor kutup silinder ditunjukkan pada gambar berikut :

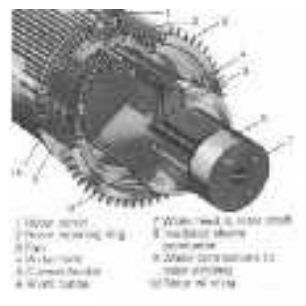

Gambar 4. Gambaran bentuk

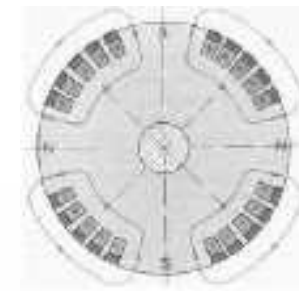

(a) rotor Non-salient (rotor silinder), $\quad$ (b) penampang rotor pada generator sinkron mercubuana.ac.id/files/.../2100601_ELektronika\%20\&\%20TTL_Modul_013.docx

\section{METODE PENELITIAN}

Penelitian dilakukan di Laboratorium Mesin-mesin Elektrik Universitas PGRI Palembang.

Peralatan yang digunakan adalah :

1. Generator sinkron 3 fasa dengan penggerak diesel

Daya

$15 \mathrm{~kW}$

Tegangan

$380 \mathrm{~V}$ (fasa ke fasa)

Frekwensi

$220 \mathrm{~V}$ (fasa ke netral)

Kecepatan

$50 \mathrm{~Hz}$

Eksitasi

$1500 \mathrm{rpm}$

45 Volt (DC)

2. Trafo step down 3 fasa

Daya : $20 \mathrm{kVA}$

Tegangan Input $\quad: \quad 380 \mathrm{~V}$ (fasa ke fasa)

Tegangan Output $\quad: \quad 30 \mathrm{~V}$ (fasa ke netral)

Merek : $\quad$ Trafindo

3. Elektroda las $3,2 \mathrm{~mm}$ dan $2,6 \mathrm{~mm}$

Pada saat pengujian dilakukan pengukuran terhadap beberapa parameter generator, yaitu :

1. Tegangan Keluaran generator

2. Arus keluaran generator

3. Putaran generator

4. Tegangan eksitasi

5. Arus eksitasi

Pengujian dilakukan dengan mengoperasikan generator untuk pengelasan, dengan 1 kepala las, 2 kepala las dan 3 kepala las. 


\section{PERHITUNGAN}

Setelah dilakukan pengujian, dilakukan perhitungan besaran-besaran sbb :

1. Fluksi magnet

$$
\begin{aligned}
& \varphi=\frac{N . l}{\Re} \\
& \frac{N}{\Re}=\mathrm{k} \quad \text { (konstanta) } \\
& \mathrm{I}=\mathrm{I}_{\mathrm{f}}=\text { arus eksitasi medan } \\
& \varphi=\mathrm{k} . \mathrm{I}_{\mathrm{f}}
\end{aligned}
$$

2. Tegangan keluaran generator

Dengan menganggap trafo yang dipakai ideal,

$\mathrm{E}_{0}=$ c.n. $\varphi$

$\mathrm{E}_{0}=$ c.n. k. $\mathrm{I}_{\mathrm{f}}$

$\mathrm{E}_{0}=\mathrm{c} . \mathrm{k} \cdot \mathrm{I}_{\mathrm{f}} \cdot \mathrm{N}$

$\mathrm{E}_{0}=\mathrm{k}_{1} \cdot \mathrm{I}_{\mathrm{f}} \cdot \mathrm{n}$

3. Perhitungan gaya lawan rotor

Gaya yang berlawanan arah dengan gaya yang dihasilkan prime mover, yaitu

$\mathrm{F}_{\mathrm{fe}}=$ B.I..$\ell$

$\mathrm{B}=\frac{\Psi}{A}=\frac{k \cdot l_{I}}{A}=\frac{k_{2} \cdot l_{I}}{A}$

Maka $\mathrm{F}_{\mathrm{fe}}=\mathrm{k}_{2} \cdot \mathrm{I}_{\mathrm{f}} \cdot \ell \cdot \mathrm{I}$

$\ell=$ panjang lintasan fluksi sebagai konstanta, maka $\mathrm{k}_{2} \cdot \ell=\mathrm{k}_{3}$

$\mathrm{F}_{\mathrm{fe}}=\mathrm{k}_{3} \cdot \mathrm{I}_{\mathrm{f}} . \mathrm{I} \quad \mathrm{I}=$ arus beban generator

\begin{tabular}{|c|c|c|c|c|c|c|c|c|}
\hline \multirow{2}{*}{$\begin{array}{c}\text { Jumlah } \\
\text { Kepala } \\
\text { Las }\end{array}$} & \multirow{2}{*}{$\begin{array}{l}\text { Elektroda } \\
\quad(\mathrm{mm})\end{array}$} & \multicolumn{2}{|c|}{$\mathrm{V}_{\text {out }}$ (Volt) } & \multirow{2}{*}{$\begin{array}{c}\mathrm{I}_{\text {out }} \\
\text { (Volt) }\end{array}$} & \multicolumn{2}{|c|}{$\mathrm{V}_{\mathrm{f}}(\mathrm{Volt})$} & \multirow{2}{*}{$\begin{array}{c}\mathrm{I}_{\mathrm{f}} \\
\text { (Amp) }\end{array}$} & \multirow{2}{*}{$\begin{array}{c}\mathrm{N} \\
(\mathrm{rpm})\end{array}$} \\
\hline & & $\mathrm{V}_{\text {nom }}$ & $\begin{array}{c}V_{\text {hs }} \text { per } \\
\text { fasa }\end{array}$ & & $V_{\text {non }}$ & & & \\
\hline \multirow{2}{*}{1} & 2,6 & 30 & 11 & 124 & 45 & 17 & 8,4 & 1475 \\
\hline & 3,2 & 30 & 9 & 175 & 45 & 14 & 14,7 & 1425 \\
\hline \multirow{2}{*}{2} & 2,6 & 30 & 11 & 124 & 45 & 13 & 12,7 & 1415 \\
\hline & 3,2 & 30 & 9 & 175 & 45 & 11 & 16,3 & 1355 \\
\hline \multirow[b]{2}{*}{3} & 2,6 & 30 & 11 & 124 & 45 & 9 & 18,3 & 1320 \\
\hline & 3,2 & 30 & 9 & 175 & 45 & 8 & 23,1 & 1215 \\
\hline
\end{tabular}

\section{HASIL DAN PEMBAHASAN}

Data Hasil Pengujian

Tabel 1. Hasil Pengujian dengan 1 kepala Las

Tabel 2. Hasil Perhitungan

\begin{tabular}{|c|c|c|c|c|c|}
\hline $\begin{array}{c}\text { Jumlah } \\
\text { Kepala } \\
\text { Las }\end{array}$ & Elektroda & $\begin{array}{c}\mathrm{V}_{\text {out }} \text { (Volt per fasa) } \\
\text { hasil pengukuran }\end{array}$ & $\begin{array}{c}\mathrm{V}_{\text {out }} \text { (Volt per fasa) } \\
\text { hasil perhitungan }\end{array}$ & Fluksi (Weber) & $\mathrm{F}_{\text {fe }}(\mathrm{N})$ \\
\hline 1 & 2,6 & 11 & 11 & $8,4 \mathrm{k}$ & $1041,6 \mathrm{k}_{3}$ \\
\cline { 2 - 6 } & 3,2 & 9 & 18,6 & $14,7 \mathrm{k}$ & $2572,5 \mathrm{k}_{3}$ \\
\hline 2 & 2,6 & 11 & 16 & $12,7 \mathrm{k}$ & $3149,6 \mathrm{k}_{3}$ \\
\cline { 2 - 6 } & 3,2 & 9 & 19,7 & $16,3 \mathrm{k}$ & $5705 \mathrm{k}_{3}$ \\
\hline 3 & 2,6 & 11 & 21,4 & $18,3 \mathrm{k}$ & $6807,6 \mathrm{k}_{3}$ \\
\cline { 2 - 6 } & 3,2 & 9 & 24,92 & $23,1 \mathrm{k}$ & $12127,5 \mathrm{k}_{3}$ \\
\hline
\end{tabular}


Dari table diatas dapat diketahui bahwa tegangan kerja mengalami penurunan untuk elektroda $2,6 \mathrm{~mm}$ dari $30 \mathrm{~V}$ menjadi $11 \mathrm{~V}$ dan dari $30 \mathrm{~V}$ menjadi $9 \mathrm{~V}$ untuk elektroda $3,2 \mathrm{~mm}$. Hal ini disebabkan adanya arus yang diserap beban dan menyebabkan jatuh tegangan.

Tegangan yang dibangkitkan generator mengalami jatuh tegangan yang sangat besar, terutama jika ketiga kepala las digunakan. Tegangan hasil perhitungan adalah tegangan yang seharusnya dibangkitkan saat pengelasan, tetapi karena arus yang diserap beban sangat besar, maka tegangan yang terukur tidaklah sebesar tegangan yang seharusnya dibangkitkan. Selisihnya merupakan jatuh tegangan di benda kerja dan di penghantar saluran serta di elektroda las.

Pada saat pengelasan, akan terjadi gaya lawan yang arahnya akan berlawanan arah dengan putaran prime mover, sehingga akan berakibat berkurangnya gaya prime mover tersebut. Hal ini akan mengurangi kecepatan putaran rotor. Semakin besar arus beban, atau semakin berat beban generator, gaya lawan akan semakin besar, sehingga kecepatan putaran generator akan semakin berkurang.

\section{KESIMPULAN}

Dari hasil pengukuran dan perhitungan dapat disimpulkan bahwa :

1. Saat generator berbeban (beban pengelasan) tegangan yang diukur lebih kecil daripada tegangan yang dibangkitkan, karena adanya jatuh tegangan di saluran, elektroda dan beban

2. Pada saat dibebani, kecepatan rotor akan berkurang, karena arus beban akan memberikan gaya lawan yang arahnya berlawanan dengan arah putaran prime mover

3. Semakin besar beban generator, gaya lawan yang terjadi akan semakin besar pula, pada penelitian ini beban yang paling besar adalah digunakannya 3 kepala las.

\section{DAFTAR PUSTAKA}

1. Eugene C. Lister, "Mesin dan Rangkaian Listrik", Penerbit Erlangga, Jakarta, 1988

2. Zuhal,'Dasar Teknik Tenaga Listrik dan Elektronika Daya”, PT Gramedia, Jakarta, 1990

3. mercubuana.ac.id/files/.../2100601_ELektronika\%20\&\%20TTL_Modul_013.docx

4. repository.usu.ac.id/bitstream/123456789/20111/3/Chapter\%20II.pdf

5. wahyukr.staff.gunadarma.ac.id/Downloads/.../5+TEORI+GENERATOR+SINKRON.p... 